\title{
CARACTERIZAÇÃO MICROBIOLÓGICA E CLÍNICA DE SURTOS DE "RED LEG" EM MINAS GERAIS E AVALIAÇÃO DO EFEITO BACTERICIDA IN VITRO DO VANTOCIL IB® PARA Aeromonas hydrophila
}

\section{MICROBIOLOGICAL AND CLINICAL CHARACTERIZATION OF "RED LEG" OUTBREAKS IN MINAS GERAIS, BRAZIL, AND EVALUATION OF IN VITRO BACTERIAL EFFECTS OF VANTOCIL IB ${ }^{\circledR}$ FOR Aeromonas hydrophila}

\section{Anna Christina de Almeida ${ }^{1}$ Luiz Eduardo Ristow ${ }^{2}$ Tânia de Toledo Martins Buelta ${ }^{3}$}

RESUMO

Com o objetivo da caracterização da ocorrência de "red leg" em Minas Gerais, avaliaram-se rãs jovens e adultas que apresentavam úlceras nas patas e dedos, derrame hemorrágico na pele da região ventral, incoordenação motora, altas taxas de mortalidade em adultos e abscessos hepáticos à necropsia. No cultivo de fragmentos de pele lesada e abscessos, foi isolado e identificado Aeromonas hydrophila. $O$ efeito bactericida do VANTOCIL IB® foi superior ao permanganato de potássio, determinado pela concentração inibitória mínima para colónias isoladas.

Palavras-chave: rãs, "red leg", Aeromonas hydrophila, vantocil, biguanida.

\section{SUMMARY}

With the objective of characterizating lhe ocurrence of "red leg" in Minas Gerais, Brazill, young and adult frogs which presented in theirpads and limbs hemorragie in the skin of the ventral region, incordination, high death rate in adults and hepatic abscess at necropsy, have been evaluated. In fragment culture ofdamage skin and abscess, Aeromonas. hydrophila hás been isolated and identified. The bactericidal effect of VANTOCIL IB® was higher than that of potassium permanganate, as determinated by the minimal inhibitory concentration for isolated colonies.

Key words: frogs, "red leg", Aeromonas hydrophila, vantocil, biguanides.

\section{INTRODUÇÃO}

Bactérias do gênero A. hydrophila são habitantes normais de ambientes aquáticos e compõem a microbiota regular de animais ectotermos e endotermos (KAY et al., 1985, SUGITA et al., 1995), sendo considerada por vários autores como patógeno emergente de veiculaçâo alimentar (ROSSI et al., 1996). Sob condições estressantes de manejo, A. hydrophila pode causar doenças com altas mortalidades em animais ectotermos (SOVERI, 1981, YADAV et al., 1996), mamíferos (LOVE \& LOVE, 1981, FEGURA \& MARRI, 1985, KAY et al., 1985) e aves (SHANE \& GIFFORD, 1985, SHANE et al., 1988).

Em rãs, essa bactéria é responsável por "red leg", enfermidade associada a más condições de higiene dos tanques e má qualidade da água (HIPÓLITO, 1995). Caracteriza-se por úlceras nas patas, mandíbulas, dedos e pele; derrame hemorrágico na região ventral e patas; mortalidades em taxas variadas, problemas locomotores e abscessos hepáticos podem estar presentes (RAFIDAH et al., 1990, HIPÓLITO, 1995). Infecções em humanos são apresentadas por intoxicação alimentar devido à ingestão de produtos

\footnotetext{
${ }^{1}$ Médico Veterinário, Doutor, Professor do Instituto de Ciências Agrárias e Medicina Veterinária da Universidade de Alfenas UNIFENAS/ICAMV, Rodovia MG 170, km 0, Campus Universitário, 37130-00, Alfenas, MG. Fone (35) 299-3165. E-mail: chris@unifenas.br. Autor para correspondência.

${ }^{2}$ Médico Veterinário. Diretor técnico do Tecsa Laboratórios.

${ }^{3}$ Estudante de graduação, Curso de Medicina Veterinária, UNIFENAS.
} 
de origem animal (BUCHANAN \& PALUMBO, 1985, HANNIENEN, 1993, YADAV et al., 1996, ROSSI et al., 1996) e/ou água contaminada (BERNAGOZZI $\boldsymbol{e t}$ al., 1997, WABURTON $\boldsymbol{e t} \boldsymbol{a l}$., 1995), com mortalidade elevada, gastroenterite e septicemia, ou como agente oportunista em infecções de feridas, meningites, osteomielites, infecções urinárias, respiratórias e oculares, principalmente em indivíduos imunossuprimidos (QUINN et al., 1994).

No Brasil, a literatura sobre infecções por esse agente é escassa, sendo descrita apenas a ocorrência da bactéria em carne bovina comercializada no Estado de São Paulo (ROSSI $\boldsymbol{e t}$ al., 1996) e em peixes no Estado de Minas Gerais (HOLANDA et al., 1998). A ocorrência em ranicultura, de acordo com relatos pessoais de produtores, está sendo cada vez mais frequente e o diagnóstico é feito somente em caráter clínico.

Para tratamento da enfermidade, é indicado antibioticoterapia à base de gentamicina, sulfametoxazol, cefalosporina e cloranfenicol (QUINN et al., 1994). Em ranicultura, além da retirada de fatores predisponentes, a indicação terapêutica é feita com antibioticoterapia ou imersão dos animais afetados em solução de permanganato de potássio a $10 \%$ ou sulfato de cobre $5 \%$ (Frog Doctor, 1997).

A utilização de antibióticos é prática difícil pela necessidade de formulações adequadas e pelo custo. A imersão em permanganato de potássio leva à perda total da pele e, em sulfato de cobre, deixa a carne escura, tomando-a inviável para consumo, se realizado próximo ao abate, o que dificulta o controle e tratamento da enfermidade, necessitando então do desenvolvimento de produtos eficientes que sejam aplicáveis economicamente.

O VANTOCIL IB ${ }^{\circledR}$ (sal de biguanida polimérica) é um biocida que tem se apresentado com características desejáveis para utilização em criações de animais, pois tem baixo poder residual em água e alimentos, reduzida toxicidade para peixes e outros microorganismos vivos em águas residuais tratadas, baixa irritabilidade para superfícies mucosas e boa ação fungistática e bactericida, sendo descrita sua utilização em avicultura (INFORMÁTICO ICI, 1997). O produto vem sendo utilizado em ranicultura sem que seja avaliada a eficiência do mesmo em qualquer parâmetro.

Este trabalho descreve a ocorrência de "red leg" em Minas Gerais, com caracterização clínica e laboratorial da enfermidade e avalia o efeito bactericida do VANTOCIL IB ${ }^{\circledR}$ sobre A. hydrophila in vitro como ensaio prévio para otimização de sua utilização em ranicultura.

\section{MATERIAL E MÉTODOS}

Quinze rãs adultas e dez jovens provenientes de duas anfigranjas localizadas no Estado de Minas Gerais, com suspeita clínica de "red leg" foram enviadas ao TECSA Laboratórios, Belo Horizonte, MG, para diagnóstico da enfermidade. Avaliaram-se os sinais clínicos e lesões à necropsia (RAFIDAH et al., 1990, HIPÓLITO, 1995) e procedeu-se análise microbiológica.

$\mathrm{O}$ isolamento foi realizado a partir de macerados de fragmentos de pele e fígado lesados em ágar sangue-dextrina-ampicilina a $28^{\circ} \mathrm{C}$ por 24 horas (HAVELAR \& VONK, 1988) e posterior identificação de colônias sugestivas através de provas bioquímicas e morfológicas (KONEMAN $\boldsymbol{e t}$ al., 1994, QUINN et al., 1994).

Para ensaio, verificando a eficiência do VANTOCIL IB® - ZENECA, as colônias identificadas foram submetidas determinação da Concentração Inibitória Mínima MIC (NATIONAL..., 1994) em paralelo ao permanganato de potássio, com modificações. Para realização da leitura $\backslash$ inoculou-se $0, \operatorname{lm} l$ de cada diluição em ágar sangue-dextrinaampicilina, conforme realizado para isolamento inicial, sendo verificada a presença de crescimento de colónias características, pois a diluição do produto no meio sem crescimento já o tomava turvo, o que poderia interferir na leitura final.

\section{RESULTADOS E DISCUSSÃO}

Nas duas propriedades avaliadas foi descrito mortalidade em todas as fases de criação, com taxas variáveis de 10 a $80 \%$, concentrando na fase de terminação. À análise clínica e macroscópica das lesões, observaram-se úlceras nas patas $(90 \%)$ e dedos (92\%), derrame hemorrágico na região ventral (80\%), dificuldade de locomoção (60\%) e abscessos hepáticos (56\%). Estes achados são compatíveis com os descritos na literatura que caracterizam clincia e patologicamente "red leg" (RAFIDAH et al., 1990, HIPÓLITO, 1995).

O crescimento de colônias características em ágar sangue-dextrina-ampicilina e ágar MacConkey, avaliadas em características morfotintoriais e submetidas a provas fisiológicas e bioquímicas (Tabela 1) apresentaram-se compatíveis com os descritos na literatura (KONEMAN et al., 1994,QUINN et al., 1994), permitindo a identificação de A. hydrophila.

O isolamento e identificação de A. hydrophila em Minas Gerais, neste trabalho, (Tabela 1) mostra que o diagnóstico laboratorial da 
Tabela 1 - Características morfologicas, fisiológicas e bioquímicas de $A$. hydrophila isolada em surto de "red leg" em Minas Gerais.

\begin{tabular}{ll}
\hline Característica avaliada & Resultados observados \\
\hline Características morfotinturiais & $\begin{array}{c}\text { Bastonetes gram negativos, tamanho } \\
\text { médio,pleomórficos de lados retos }\end{array}$ \\
& Presente \\
Beta hemólise em sangue ovino & Positiva \\
Oxidase & Positiva \\
Catalase & Positiva \\
Mobilidade & Positiva \\
DNAse & Positiva \\
Indol & Positiva \\
Produção de gás (glicose) & \\
Descarboxilases: & \\
Lisina & Negativa \\
Ornitina & Negativa \\
Arginina & Positiva \\
Esculina & Positiva \\
Fermentação: & \\
Arabinose & Positiva \\
Sacarose & Negativa \\
Inositol & \\
\hline & \\
\hline & \\
\hline & \\
\hline
\end{tabular}

enfermidade em ranários pode ser realizado de forma relativamente simples, rápida e barata, permitindo o reconhecimento da enfermidade, o que facilitaria o direcionamento das medidas de controle a serem implantadas, reduzindo perdas na produtividade dos animais.

Ao se tratarem de animais ectotermos frios fica difícil de estabelecer com exatidão os responsáveis diretos pelas enfermidades, pelo fato de, normalmente, serem agentes microbianos pertencentes à microbiota natural do animal estando no ambiente aquático, e, também por serem oportunistas e ubiquitários (HIPÓLITO, 1994). As enfermidades ocorrem em certas condições ainda não bem estabelecidas, sendo o estresse um fator predisponente constante, além da participação de outros agentes físicos, químicos e biológicos (HIPÓLITO, 1995), sendo necessária a determinação destes para controle de enfermidades.

$\mathrm{Na}$ determinação da $\mathrm{MIC}$, os resultados para o VANTOCIL IBß foram em diluições superiores aos do pennanganato de potássio, isto é, até a diluição $10^{-3} \mathrm{M}$ do produto, este ainda apresentava atividade bactericida (Tabela 2). O tratamento de enfermidades em ranicultura, como em qualquer exploração pecuária deste nível, acarreta custos com medicamentos, mudanças na rotina do ranário, presença de resíduos na água e
Tabela 2 - Determinação da concentração inibitória mínima do VANTOCIL $\mathrm{IB}^{\oplus}$ e permanganato de potássio para $A$. hydrophila isolada de surtos de "red leg" em Minas Gerais.

\begin{tabular}{|c|c|c|c|c|c|}
\hline \multirow[b]{2}{*}{ Produto } & \multicolumn{5}{|c|}{ Diluições } \\
\hline & $10^{-1}$ & $10^{-2}$ & $10^{-3}$ & $10^{-4}$ & $10^{-5}$ \\
\hline VANTOCIL IB ${ }^{\oplus}$ & Neg* & Neg & Neg & Pos** & Pos \\
\hline Permanganato de potássio & $\mathrm{Neg}$ & Pos & Pos & Pos & Pos \\
\hline
\end{tabular}

* Ausência de crescimento bacteriano.

** Presença de crescimento bacteriano.

carne, custos excessivos, necessidade de via de administração que facilite o manejo, além de que, no caso específico de "red leg", toma a carne imprópria para o consumo (HIPÓLITO, 1995). A utilização de VANTOCIL IB ${ }^{\circ}$, pelos resultados aqui apresentados, pode vir a ser um produto que supra algumas das deficiências encontradas em produtos bactericidas.

Torna-se necessária a avaliação dos efeitos do produto in vivo para ranicultura, considerando a natureza dessa exploração, pois as excretas dos animais ajudam a manter o índice de microrganismos no ambiente, como também o custo/benefícios em relação aos tratamentos até então preconizados.

\section{AGRADECIMENTOS}

Tecsa Laboratórios. Zeneca Biocidas. Zeneca Biocidas.

\section{REFERÊNCIAS BIBLIOGRÁFICAS}

BERNAGOZZI, M., BIANUCCI, M. SACHETTI, R. Prevalence of Aeromonas spp. to surface waters. Water Environinent Research., v.67, n.7, p.1060-1064,1997.

BUCHANAN, R.L., PALUMBO, S.A. Aeromonas hydrophila and $A$. sobris as potential food poisoning species: a review. Journal of Food Safety, v.7, n.1, p.15-29,1985.

FROG DOCTOR- Informação via totemethttp://www.teleport.com/ dstroy/info/sick.html. 1997.

FEGURA, A., MARRI, L. Isolation of Aeromonas sp. From animaes [swine] European Journal of Clinical Microbiology, v.4, n.3, p.354-355, 1985.

HANNIENEM, M.L. Ocurrence of Aeromonas sp. in samples of ground meat chicken. International Journal of Food Microbiology, v. 18, n.4, p.339-392,1993.

HAVELAR, A.H., VONK, M. The preparation of ampicilin dextrin agar for the enumeration of Aeromonas in Maltor. Letters in Applied Microbiology, v.7, p.167-171, 1988. 
HIPÓLITO, M. Patologia e manejo sanitário dos organismos aquáticos. ABC - Rã, v.1, n.5, p.1-2,1994.

HIPÓLITO, M. Manejo sanitário to: TECHNOFROG, 95, 1995, Viçosa. Anais... Viçosa: 1995. v.II. p. 199-207.

HOLANDA, E.D., LIMA, E.C., MARTINS, N.E., $\boldsymbol{e}$ t al Ocorrência de Aeromonas sp em Tilápias (Oreochromis spp). Belo Horizonte, MG, 1998. to: ENCONTRO DE PESQUISA DA ESCOLA DE VETERINÁRIA, UFMG, 16, 1998, Belo Horizonte, MG. Anais... Belo horizonte: Universidade Federal de Minas Gerais, Escola de Veterinária, Napq. 1998. 208p. p.70

INFORMATIVO TÉCNICO ICI. VANTOCIL IB® • São Paulo, ICI, 1997. 40p.

KAY, B.A., GUERRERO, C.E., SACK, R.B. Media for isolation of Aeromonas hydrophila. Journal of Clinical Microbiology, v. 22, n.5, p.888-890,1985.

KONEMAN, E.W., ALLEN, S.D., JANDA, W.M., et al Introduction to diagnostic microbiology. Philadelphia: Lippincott, 1994. 527p

LOVE, R.J., LOVE, D.N. Aeromonas hydrophila isolated from polyarthritis in a calf. Australian Veterinary Joumal, v.61, n. 2 , p. 65,1981

NATIONAL COMITTEE FOR CLINICAL LABORATORY STANDARDS $3^{\text {rd }}$ ed. Vilanova: NCCLS,M7-A3, 1994.. 28p.

QUINN, P.Q..CARTER, M.E, MARKEY, B., et al. Clinical veterinary microbiology. 4 ed. London: Wolfe, 1994. 648p.
RAFIDAH, J. ONG, B.L. SAROJA, S.J. Outbreak of "red leg" in Aeromonas hydrophila infection in frogs. Joumal Veterinary, Malasya, v.2, n.2, p.139-142,1990.

ROSSI, O.D.JR., FILHO, A.N., AMARAL, L.A. Ocurrence of Aeromonas species in commercial cattle meat in Jaboticabal, São Paulo, Brazil, and a comparation study of isolation media. Ars Veterinária, v.12, n.1, p.69-73,1996.

SHANE, S.M., GIFFORD, D.H. Prevalence and pathogenicity of . Aeromonas hydrophila. Avian Diseases, v.29, n.3, p.681$689,1985$.

SHANE, S.M., HARRINGTON, K.S., MONTROSE, M.S., et al The ocurrence of Aeromonas hydrophila in avian diagnostic submisson. Avian Diseases. v.28, n.3, p.804-807,1988.

SOVERI, T. Observations of bacterial diseases of captive snakes in Finlandia. Nordisk Veterinaermedicin, v.36, n. 1/2, p.3842,1981 .

SUGITA, H., TANAKA, K., YOSHIMANI, M., $\boldsymbol{e}$ t al Distribuition of Aeromonas species in the intestinal tracts of river fish. Applied Enviromental Microbiology, v.61, n.l 1, p.4128-4230,1995.

WABURTON, D.W., McCORMICK, J.K., BOWEN, B. Survival and recovery of $\boldsymbol{A}$. hydrophila in water: development of methodology for testing blotted water in Canada. Canadian Journal of Microbiology, v.4, n.2, p.145-148, 1995.

YADAV, A.S., SINGN, B.R., KAPOOR, K.N., et al. Isolation of iatrogenic Aeromonas from fish Indian Journal of Veterinary Research, v.5, n.1, p.45-48,1996.

Ciência Rural, v. 30, n. 4, 2000. 